$\Phi=\Phi$

\title{
Effect of public health expenditure on health status in Ghana
}

\author{
Micheal Kofi Boachie ${ }^{1 *}$, K. Ramu ${ }^{2}$ \\ ${ }^{1}$ Research Scholar, Department of Economics, Annamalai University, Annamalai Nagar, Tamil Nadu, India \\ ${ }^{2}$ Assistant Professor, Department of Economics, Annamalai University, Annamalai Nagar, Tamil Nadu, India \\ *Corresponding author E-mail:mkboachie@gmail.com
}

\begin{abstract}
Health is an outcome indicator of economic growth and development of a country. Healthcare is a major factor for health status. In this regard, healthcare expenditure is a vital input for the health production function. In this context, this study examined the effect of public health expenditure on health status in Ghana. Annual time-series data on infant mortality rate, real per capita income, literacy levels and female labour force participation rate for the period 1990-2012 have been used. Infant mortality rate was used as the output variable. To test the relationship between input-output variables, Ordinary Least Squares and Newey-West regression techniques were used. The regression estimates suggest that real per capita income, public health expenditure, education and female presence in the labour market were negatively related to infant mortality rate. However, the elasticity coefficients of female participation in the labour market and real per capita income were statistically insignificant at 5\% level. This study concludes that public health expenditure and literacy/education improve health status by reducing infant mortality. The favourable effect of education or literacy on health is greater than that of public health spending whereas the effect of real per capita income on health was found to be weak. The findings provide the impetus for government to raise literacy level and its health spending in the country to promote health.
\end{abstract}

Keywords: Public Health Spending; Ghana; Infant Mortality; Health Status.

\section{Introduction}

Good health is an asset. It serves as the means towards achieving all other individual and societal goals. Healthy people are more likely to take up educational and employment opportunities for [higher] earnings. Labour productivity is higher among the healthy with low absenteeism. Indeed, the role of health in growth and development has long been acknowledged (Mushkin 1962, Bloom et al. 2004). Cole and Neumayer (2006) also contend that poor health partly accounts for the underdevelopment in some parts of the world. Improvements in health do not only enhance the productivity or earnings of the nation (or the individual) but also improve the well-being of the people (Sen 1985, 1988; Grossman 1972, 2000; Novignon et al. 2012a). As such, it serves as one of the important measures of complete welfare and progress of people. Many people are impoverished due to poor health. Consequently, the level of mortality (e.g. infant and under-five) has been used as an indicator of health status and well-being or the level of impoverishment in a country.

In recent years, improving health conditions of people, especially among infants and children, has been the focus of policymakers. Children, especially infants, are the most vulnerable group in society. While some children escape from such childhood killer diseases as measles and diphtheria into adulthood, others die before their first birthday. Even for those who are fortunate to celebrate their first birthday some die before age five. Reducing mortality among children, thus, improves health status and welfare of children while securing future workforce for the nation. The role of healthcare services is crucial in improving health status. Indeed, [public] provision of healthcare services has been recognised as one of the important ways to improve living conditions and human welfare (UNDP 1990, World Bank 1993).
Availability of and access to improved healthcare services reduces mortality, and financial risk among the population while addressing poverty issues. In this regard, adequate and efficient health spending remains crucial in improving health status, and the role of the state is well emphasised (Heijink et al. 2013, Arthur 2013, Novignon et al. 2012b, Bokhari et al. 2007, Anyanwu \& Erhijakpor 2007). Thus, public health spending will improve the overall health capital and well-being via enhanced accessibility and affordability to healthcare services, especially for the poor. Healthcare is, thus, an important input to the health production function (Grossman 1972, 2000; Wagstaff 1986). The implication is that, healthcare is one of the important avenues to reduce infant mortality towards welfare improvement.

In most developing countries, where child mortality, communicable diseases, income poverty and inequality remain high, private expenditures on healthcare dominate. Further, out-of-pocket expenditure remains a major component of private health expenditures in most of these countries, especially in countries with no social health insurance. This restricts access to medical care, particularly for the poor. This, partly, formed the basis for the adoption of the Millennium Development Goals (MDGs) in 2000 to salvage the growing impoverishing population. Reducing child mortality by two-thirds was one of the health targets of the MDGs (UNDP, 2003). In the spirit of the MDGs, African Union governments also pledged to commit 15 percent of their respective national budgets, annually, to improve the health and well-being in Africa by the end of 2015. However, as in 2012, the majority of African countries, including Ghana, did not achieve this target (UNAIDS 2013, World Bank 2014).

In Ghana, averagely, public expenditure on healthcare has increased by about 74 percent in the last two decades. However, this expenditure as proportion of GDP is low as compared to the global average of 5.76 percent (World Bank, 2014). Specifically, 
public spending on healthcare rose, from 1.7 percent of GDP in 1990 to 2.96 percent of GDP in 2012. Between 1990 and 2012, public healthcare expenditure has averaged 2.75 percent of GDP annually. For instance, in 2007, government allocation to health sector represented 16.24 percent [3.75 percent of GDP] of total government expenditure, an allocation that exceeded the Abuja target. This period witnessed significant investments in the health sector, mostly in the form of construction of new health facilities (e.g. CHPS, and clinics), hiring and training healthcare personnel, upgrading of existing facilities and other health infrastructure in the country.

In recent past, however, there has been a gradual decline in government allocation to the health sector. For instance, spending between 2008 and 2012 averaged 12.32 percent of total government spending and, in particular, only 9.72 percent of total government spending in 2012 went into health (World Bank, 2014). Much of these expenditure cuts have been born out of cost containment and the aim to reduce the government budget deficit While government spending on health (as proportion of total government spending) has seen a downward trend, there has been a remarkable improvement in health status. The progress is seen from the rising life expectancy at birth and declining mortality among children. For instance, life expectancy at birth has improved from 56 years in 1990 to 61 years in 2012. Infant and under-five mortality rates have also declined from 80 and 128 (per 1000 live births) in 1990 to 53 and 80 in 2012 respectively (World Bank, 2014). Given this background, it becomes imperative to assess how public health expenditure has contributed to the improved health status in Ghana, and to find, if any, other factors accounting for the improvements. Thus, the present paper seeks to examine the role of public health expenditure on health status, especially infant mortality, which is one of the macro health indicators of human health. Such analysis would provide information on the efficiency public health expenditure. Therefore, the present study is of high significance from the policy perspective.

\section{Literature review}

\subsection{Theoretical review}

Health is an important component of human capital that yields economic returns (Mushkin 1962, Bloom et al. 2004). According to Grossman (1972, 2000), health is a durable capital stock producing healthy time as an output for both market and non-market activities. This healthy time yields two main benefits: utility and earnings (i.e., non-market and market activities) to the individual. These benefits oblige people to invest in their health following depreciation due to time (i.e., age). Analogous to the individual, the state also benefits from good health in the form of improved welfare and higher labour-hours and productivity hence the state's investment in health.

Consumption of healthcare or medical services is considered one of the avenues to invest in health subject to one's budget and time. While healthcare consumption represents the investment in health at the individual level, provision of and improvement in healthcare infrastructure, including healthcare personnel, constitute health investment at the state level. Thus, the state makes available healthcare facilities and personnel whereas individuals utilize these facilities to improve their health status. Thus, individual's investment in health via medical care consumption is dependent on the availability of and access to healthcare services. Within the production function framework, healthcare is considered one of the several inputs in the health production function. Thus, healthcare is seen as input in the production of the commodity "good health" such as low mortality, and higher life expectancy (Wagstaff, 1986). Thus, healthcare is considered an input in producing, for example, zero or low mortality, and higher life expectancy hence the presence of health expenditure in the health production. Regardless of the approach used, healthcare is one of the means for individuals to improve their health status. However, the ability of individuals to undertake such investment or production activity is dependent on the availability of and access to health resources, whether provided by the public or private. Following the externality that health presents, income poverty, welfare, and inequity issues, government provision of healthcare (including public health services) is necessary (Sen 1988, Kethineni 1991, World Bank 1993). The proposition in the present study is that if government role is needed in the healthcare market, then it is necessary to assess the contribution of the expenditure by government towards the improvement in health status within the framework of the health production function.

\subsection{Empirical studies}

Several studies have explored the relationship between health spending and health status both in developing and developed countries. While some have focused on the effect of total health spending, others have concentrated on revealing the relative roles of private and public health spending in improving health status. Anand and Ravallion (1993) applied OLS estimation technique and examined the relative roles of private incomes and public services using cross-country data for 22 countries. They found that healthcare spending, particularly public spending on health, promotes health status (i.e., life expectancy at birth). In Canada, Crémieux et al. (1999) assessed the impact of healthcare spending on health outcomes (i.e., gender specific life expectancy and infant mortality). After controlling for per capita income, physician per person and other socio-economic factors, healthcare spending was relevant for promoting health outcomes.

Further, Gupta et al. (2001, 2002) have found public health expenditure to be an important factor affecting health status. The results were obtained after controlling for consumption and literacy levels. The findings reported from 111 developing and transition countries by Baldacci et al. (2002) also support the argument that public health spending is effective in improving health status. A similar study by Issa and Ouattara (2005) found that health expenditure reduces infant mortality. However, public health spending was only effective in reducing infant mortality at lower levels of development. At higher levels of development, private expenditure on health was effective in reducing infant mortality. Again, Gottret and Scieber (2006) have reported similar findings from 113 countries that public health expenditure is important in promoting health outcomes in low-and-middle-income countries.

In OECD countries, Berger and Messer (2002) found a negative relationship between total health expenditure and mortality rates. However, after disaggregation, public health spending was positive on mortality suggesting that public health expenditure increased mortality in the 20 OECD countries considered. Also, in 15 EU countries Nixon and Ulmann (2006) have found that healthcare expenditure is very important in reducing infant mortality though its contribution to gender specific life expectancy was marginal. Likewise, very recent results from OECD and Eastern Mediterranean countries have confirmed the role of health expenditure, particularly public spending, in promoting health status (Heijink et al. 2013, Homaie et al. 2013). The studies on Sub-Saharan Africa have also provided a justification for health expenditure, especially public. Thus, employing various estimation techniques these studies have shown that health expenditure, particularly public health spending, play an important role in improving health status (Arthur 2013, Novignon et al. 2012b, Bokhari et al. 2007, Anyanwu \& Erhijakpor 2007).

While several studies have established that public health spending is one of the important factors accounting for the improvement in health status, others have found little or no impact. Thus, such studies found public health spending to be ineffective in improving health status (such as reduction in infant mortality). For instance, Berger and Messer (2002), Santerre et al. (1991), Musgrove (1996), Filmer and Pritchett (1997, 1999), Or (2001), and World Bank (2004) found public health spending to be 
ineffective in promoting health status. In effect, these studies suggest that public health expenditure plays little or no role in improving health status. Compa-Keyeke et al. (2013) find that public health expenditure is negatively related to infant mortality in Ghana but is insignificant after controlling for health insurance, per capita income and the number of physicians. They, however, find the elasticity coefficients of health insurance, per capita income and the number of physicians to be positive on infant mortality though per capita income was statistically insignificant. In most of these studies, the effect of per capita income, education, the presence of females in the labour market, number of physicians, and other socio-economic factors have been controlled Following from the literature, the efficacy of public health spending on health status remains elusive. While copious literature exists on the theme, literature on Ghana is scanty. Again, most of the studies have been cross-national in nature that might accoun for the absence of a link between public health spending and health status. In deviating from Compa-Keyeke et al. (2013), the present study uses a larger sample size whilst accounting for the efficiency of health production and the effect of female participation in the labour market on infant mortality. These factors might influence health status.

\section{Methodology}

\subsection{Data and definition of variables}

In the present study, annual time series dataset covering the period 1990 to 2012 have been used. The choice of this period is based on data availability. The study sourced data from World Development Indicators (2014 Excel Database) and various publications of the World Bank (e.g. Peters et al. 1999) regarding health and health expenditures. Infant mortality rate (IMR) per 1000 live births is used as a measure of health status ${ }^{1}$. Guided by production theory and previous empirical literature on the subject matter, the control variables are real per capita income (per capita GDP), literacy level among the population, and female labour force participation rate. Further, per capita GDP (constant 2005 USD) is used to measure per capita income, and public health expenditure is measured as percent of GDP. Literacy level (education) among the population is measured by gross secondary school enrolment rate. Since there was no available data on literacy levels, secondary school enrolment rate (gross \%) was used to proxy the level of literacy in Ghana ${ }^{2}$. Finally, the female labour force participation rate represents the proportion of female population of age 15 years or older that is economically active.

\subsection{Model Specification and data analysis}

A simple model of health status (i.e., infant mortality rate) is presented as follows:

$Y_{t}=\beta X_{t}+\varepsilon_{t}, t=1 \ldots T$

Where $Y_{t}$ is the dependent variable, health status, at time $t$, and $X$ is a vector of independent variables influencing health status, and also includes the intercept term while $\beta$ is a vector coefficients of the independent variables. $\varepsilon_{\mathrm{t}}$ is the error term which is assumed to be normally distributed with zero mean and constant variance. The operational model is specified below:

$\mathrm{HS}(\mathrm{IMR})_{t}=\delta+\beta_{1} \mathrm{RPGDP}_{t}+\beta_{2} \mathrm{PUHE}_{t}+\beta_{3} \mathrm{EDU}_{t}+\beta_{4} \mathrm{FLFP}_{t}+\varepsilon_{\mathrm{t}}$

\footnotetext{
${ }^{1}$ Aside infant mortality rate, life expectancy at birth, maternal mortality ratio, crude death rate, adult survival rate, and under-five mortality are also used to proxy health status.

${ }^{2}$ Due to missing values on secondary school enrolment for some years, we interpolated the data to fill the gaps for those years in which enrolment rates were missing.
}

HS is the observed health status (infant mortality rate per 1000 live births (IMR)) at time t.

RPGDP is the real per capita income. Real per capita income serves as control variable for utilisation of healthcare services since income is an influencing factor in health seeking behaviour. PUHE represents public expenditure on health while EDU represents literacy level and it captures the efficiency with which health is produced (Grossman 1972, Wagstaff 1986).

FLFPR is the female labour force participation rate and it captures the effect of female employment on home health production for children or how their presence on the labour market supplement family income to command more health inputs (Santerre et al. 1991).

$\varepsilon_{\mathrm{t}}$ And $\delta$ are respectively the error term and intercept. In order to capture the elasticities while correcting any skewness in the data, equation (2) is estimated using natural logarithmic form of the series. Thus, the estimated equation is in the logarithmic form:

$$
\begin{aligned}
& \text { LNHS (IMR) } \\
& \beta_{4} \text { LNFLFP }_{t}+\varepsilon_{\mathrm{t}}
\end{aligned}
$$

Equation (3) is estimated with Ordinary Least Squares to determine the effect of the independent variables on health status, i.e. infant mortality rate. Diagnostic test was performed to ascertain the robustness of the regression estimates. This test indicated presence of serial correlation which necessitated the use of Newey-West estimator to check the robustness of the OLS estimator.

\section{Results and discussion}

\subsection{Results}

The ordinary least squares regression was used to examine the effect of public health spending on infant mortality rate while controlling other health correlates: real per capita income, literacy and female labour force participation rate. The overall model was good since the p-value for the F-statistic was 0.000. This implies that at least one of the regression coefficients was not equal to zero. The regression estimates are presented in Table 1.

\begin{tabular}{lcc}
\multicolumn{3}{c}{ Table 1: Estimates of the Impact of Public Health Spending on IMR } \\
\hline \multirow{3}{*}{ Regressors } & Panel A & Panel B \\
& OLS Estimator & Newey-West Estimator \\
& Coefficient & Coefficient \\
\hline \multirow{2}{*}{ LNRPGDP } & $-0.265^{* *}$ & $-0.265^{*}$ \\
& $(0.123)$ & $(0.139)$ \\
LNPUHE & $-0.106^{* * *}$ & $-0.106^{* * *}$ \\
& $(0.023)$ & $(0.032)$ \\
LNEDU & $-0.328 * *$ & $-0.328 * *$ \\
& $(0.138)$ & $(0.144)$ \\
LNFLFPR & -0.246 & -0.246 \\
& $(0.412)$ & $(0.377)$ \\
Constant & $8.174 * * *$ & $8.174 * * *$ \\
& $(2.000)$ & $(1.866)$ \\
Obs & 23 & 23 \\
F-statistic & 140.06 & 156.91 \\
P-value (F) & 0.000 & 0.000 \\
Adj.R & 0.915 & 0.915 \\
\hline$*(* *) * *$ denotes significance at 10\%, 5\% and 1\% respectively \\
Standard errors in parenthesis
\end{tabular}

After employing the OLS estimator, about 92 percent of the changes in health status as measured by infant mortality rate was explained by the independent variables presented in equation (3) and also indicates the goodness of fit of the empirical model. Further, all the estimated elasticity coefficients fell within the 95 percent confidence interval. Again, three out of the four explanatory variables: real per capita income, public health spending, and education were found to be statistically significant in influencing infant mortality rate in Ghana during the study period. 
However, the diagnostic test for the OLS estimates revealed some shortfalls. Thus, there was the presence of serial correlation as shown by the LM test while no heteroskedasticity was found. While the Breusch-Pagan-Geofrey (BPG) test could not reject the null hypothesis of no heteroskedasticity $(\mathrm{F}=0.318, \mathrm{p}=0.862$; Obs $* \mathrm{R}^{2}, \mathrm{p}=0.823$ ), the LM test rejected the null hypothesis of no serial correlation $\left(F=11.315, p=0.001 ;\right.$ Obs $^{*} R^{2}=13.474$; $\mathrm{p}=0.001$ ). Thus, serial correlation was present in the residuals whereas heteroskedasticity was absent. The normality test also suggests that the variables were distributed normally since the null hypothesis of normal distribution could not be rejected (Jacque-Bera $=2.057 ; \mathrm{p}=0.359)$. Further, the diagnostics revealed some degree of multi-collinearity among the variables as shown by the correlation matrix of the estimated coefficients. However, the degree was not considered severe. As already indicated, the presence of serial correlation necessitated the use of Newey-West estimator to remedy serial correlation problem (see Panel B in Table 1).

There was a change in the standard errors after using the Newey-West estimator as well as the p-values for the elasticity coefficients. However, there was no change in the elasticity coefficients. Real per capita income achieved significance at 10 percent level after correcting for serial correlation in the residuals from the OLS estimator whereas public health spending, literacy/education and female labour force participation rate maintained their significance levels at 5 percent (see Panel B, Table 1). Thus, Newey-West estimates were robust in that there was no serial correlation and heteroskedasticity in the residuals. In this regard, the Newey-West estimator is adopted in our analysis. The elasticity coefficient of real per capita income was negative (i.e., -0.265) and statistically significant at 10 percent level in influencing infant mortality rate. Thus, it was statistically insignificant at 5 percent level. Of particular interest is the elasticity coefficient of public health spending. As shown in Table 1 , the elasticity coefficient of public health spending was negative (i.e., -0.106) and statistically significant on infant mortality at 1 person level. The results also show a 5 percent level significant negative relationship between literacy level (education) and infant mortality rate within the period under study. Specifically, the elasticity coefficient of education or literacy level was -0.33 Finally, the elasticity coefficient of female participation in the labour market was negative. It was, however, statistically insignificant on infant mortality.

\subsection{Discussion}

In the present study, the effect of public health spending on infant mortality has been estimated after controlling for the effects of real income per head, literacy, and female labour force participation rate. Our findings suggest that 10 percent increase real per capita income will cause infant mortality to fall by 2.65 percent. However, this negative effect was not statistically strong. The lower significance of real per capita income in reducing infant mortality strongly lends support to similar arguments alluded to by Anand and Ravallion (1993) that social outcomes such as health status can be enhanced through reduction in income poverty. Thus, per capita income growth alone does not matter for reduction in infant mortality. Compah-Keyeke et al. (2013) also found that real per capita income is insignificant in explaining health status in Ghana. Thus, affluence or opulence alone is not enough to enhance welfare (Sen 1985, 1988).

The present finding on real per capita income deviates from those reported by (Novignon et al. 2012b, Bokhari et al. 2007, Issa \& Ouattara 2005, Homaie et al. 2013, Filmer \& Pritchett 1997, 1999) from cross-national data who found that income is an important factor in improving health. Thus, real per capita income plays very little role in mediating the health of the population, particularly in reducing infant mortality. The results on real per capita income could be due to high-income poverty and rising income inequality, and thus making growth in real per capita income ineffective in promoting health. Though there is no complete data on poverty, available data suggests that about 24 percent of the population live below the national poverty line (World Bank, 2014). This suggests that quite a significant portion of the population is poor.

Public health expenditure has been found to be one of the factors affecting health status in Ghana. As shown in Panel B, Table 1, government health spending exerts a strong negative influence on infant mortality. More precisely, our findings suggest that infant mortality rate tends to fall by 0.106 percent if public spending on health is increased by 1 percent. Thus, as government increases its health spending, the level of infant mortality falls. This is because essential health service like immunization and postnatal services for infants and under-five are usually provided by government at no cost to parents. Recently, the National Health Insurance Authority decoupled children, especially infants and under-fives, from their parents, which has enhanced their access to healthcare services. This, perhaps, explains the effectiveness of government spending. This finding corroborates the results of (Heijink et al. 2013, Arthur 2013, Novignon et al. 2012b, Bokhari et al. 2007, Anand \& Ravallion 1993, Gupta et al. 2001, 2002; Baldacci et al. 2002) among others suggesting that government has an important role in improving health status.

However, our findings contradict earlier results by inter alia Santerre et al. (1991), Musgrove (1996), Filmer and Pritchett (1997, 1999), Or (2001), World Bank (2004), and Compa-Keyeke et al. (2013) that public health spending is ineffective in enhancing health status. For example, contrary to Berger and Messer's (2002) report that public health expenditure causes more mortality, public health spending in Ghana reduces mortality. The infectiveness of public sector intervention in improving health status reported by most of the earlier studies could be due to their aggregation of the countries under study.

Indeed, most of these studies focused on cross-country analysis where differences in data accounting might exist. Again, most of the studies reporting insignificant negative effect and/or positive influence of public health spending on mortality were done for developed countries where health inputs abound. In fact, the findings of Compa-Keyeke et al. (2013) on Ghana might have resulted from small sample size and their neglect of education as an important input in the health production function. The present study on Ghana alludes to arguments advanced by (Gupta et al. 2001, 2002; Baldacci et al. 2002, Issa \& Ouattara 2005) and others that public health spending is effective in promoting health status at lower levels of development or in low-income countries than in developed or higher income countries.

Education is an important input in the health production function since it determines the efficiency in health input combination. The implication of our findings is that raising literacy levels by 1 percent has the potential to reduce infant mortality rate by 0.33 percent. This elasticity coefficient is higher than real per capita income and public health spending as shown in Table 1. The finding that a rise in literacy rate leads to fall in infant mortality is a confirmation of Grossman's $(1972,2000)$ and Wagstaff's (1986) theory of demand for health that education increases the efficiency of health production. Thus, educated population are more efficient in health production than illiterate population. This greatly underscores the importance of education, i.e. formal schooling, in promoting health status. The reason is that educated people are more likely to follow advice given by health professionals than the illiterate ones. Thus, they are able to follow prescriptions and also choose the right health inputs for children than people with no formal schooling. In fact, similar findings relating to the negative effect of education on mortality have been reported (Santerre et al. 1991, Filmer \& Pritchett 1997, 1999; Issa \& Ouattara 2005, Bokhari et al. 2007, Anyanwu \& Erhijakpor 2007).

Though insignificant in reducing infant mortality, the negative sign of female labour force participation rate is consistent with the findings of Santerre et al. (1991). These authors have argued that female participation in the labour market improves family income that enhances their command over commodities including health inputs to help improve the health of children. Perhaps, this is the reason for the negative elasticity coefficient. In the present study, 
however, the presence of females in the labour market had no significant effect on infant mortality within the study period.

\section{Conclusion}

This study has examined the role of public health spending in promoting health status in Ghana during the last two decades. The findings suggest that public health spending and education (literacy) have contributed significantly to the improved health conditions achieved between 1990 and 2012. Real per capita income played a minimal role in improving health. The results, from Newey-West estimator, suggest that raising literacy/education level and public expenditure on healthcare are very crucial in promoting health status. The findings have some implications for policymakers.

First, honouring the Abuja declaration will be a step in the right direction. Thus, government should increase its allocation to the health sector. For instance, increased government allocation will help expand the "CHPS compound" concept into most rural areas to enhance access to and use of primary healthcare services, especially for children below twelve months. Again, scaling-up immunization programmes, particularly in rural areas, will help reduce infant mortality further, and this will require enough funding from government. Aside health spending, government should pay attention to education since literacy has been found to reduce infant mortality significantly at higher rates than health sector spending and income. Thus, policies should gear towards improving enrolment in schools, at least to the secondary school level, to help raise literacy levels. The compulsory and free provision of basic education, enshrined in the 1992 constitution, was a step in the right direction. This could be expanded to include secondary education. The government should not relent on its efforts in removing "schools under trees" while renovating existing educational infrastructure at the basic and secondary levels to enhance enrolment as well as completion rate. The free distribution of books and uniforms to pupils in basic schools should be enhanced, and should be made in areas where poverty is acute to improve enrolment. Teachers should also be given incentives such as study leave, transportation and accommodation packages, especially for those in rural areas where enrolment and completion rates are low. In addition, they could be given extra allowance conditioned on students' performance in West African Exams Council's annual examinations.

Though real per capita income was not statistically significant at conventional levels, government policies aimed at reducing income poverty and income inequality will improve the welfare of the people. This could be the reason for the results on real per capita income. Reducing income poverty and inequality will enhance people's ability to consume more goods and services, including healthcare and education. By this, the policies should aim at creating educational opportunities and jobs for the people. For instance, encouraging the export sector (local production) would generate more jobs to improve incomes and raise the per-capita GDP of the nation. Overall, government should invest in the people by allocation funds towards health and education while reducing income poverty and inequality. This will help improve the health and literacy level for the overall welfare of the people.

The present study is limited in some respects. First, large number of observations could not be used due to data paucity. Thus, small sample is a shortfall of the present study. Given that private health expenditure accounts for a significant component of total health spending, further studies should incorporate private health expenditures to assess the relative roles of the public and private sectors in promoting health in Ghana. Further, the factors considered in the present study are not exhaustive since many other factors influence health status, especially infant mortality. Future studies should, therefore, incorporate these and other factors in studying the correlates of infant mortality and/or other indicators of health status to help inform policy.

\section{Acknowledgement}

The insightful comments from the anonymous reviewers and Daniel Sakyi $(\mathrm{PhD})$, Department of Economics, KNUST Kumasi, Ghana, are gratefully acknowledged.

\section{Abbreviation}

OECD: Organisation for Economic Cooperation and Development EU: European Union

SSA: Sub-Saharan Africa

CHPS: Community Health Planning Services

LM: Breusch-Godfrey Lagrange Multiplier Test for Serial Correlation

\section{References}

[1] Anand S, \& Ravallion M (1993) Human Development in Poor Countries: On the Role of Private Incomes and Public Services, the Journal of Economic Perspectives, 7(1): 133-150. http://dx.doi.org/10.1257/jep.7.1.133.

[2] Anyanwu JC, \& Erhijakpor AEO (2007) Health Expenditures and Health Outcomes in Africa, Economic Research Working Paper No 91 (December 2007), African Development Bank.

[3] Arthur E (2013) Health Expenditure, Health Outcomes and Economic Growth in Sub-Saharan Africa, an Unpublished $\mathrm{PhD}$ (Economics) Thesis, Department of Economics and Statistics, University of Benin, Nigeria.

[4] Baldacci E, Guin-Siu MT, \& Mello L (2002) More on the Effectiveness of Public Spending on Health Care and Education: A Covariance Structure Model, IMF Working Paper WP/02/90, Washington, International Monetary Fund.

[5] Berger MC, \& Messer J (2002) Public financing of health expenditures, insurance, and health outcomes, Applied Economics, 34(17):2105-2113. http://dx.doi.org/10.1080/00036840210135665.

[6] Bloom DE, Canning D, \& Sevilla J (2004) the Effect of Health on Economic Growth: A Production Function Approach, World Development, 32(1):1-13. http://dx.doi.org/10.1016/j.worlddev.2003.07.002.

[7] Bokhari FAS, Gai Y, \& Gottret P (2007) Government health expenditures and health outcomes, Health Economics, 16(3): 257-273. http://dx.doi.org/10.1002/hec.1157.

[8] Cole MA, \& Neumayer E (2006) the Impact of Poor Health on Total Factor Productivity, Journal of Development Studies, 42(6): 918-938. http://dx.doi.org/10.1080/00220380600774681.

[9] Compah-Keyeke G, Gyimah Sackey FG, \& Azinim MA (2013) Public Expenditure and Health Status in Ghana, Journal of Economics and Sustainable Development, 4(11):88-99.

[10] Crémieux P-Y, Ouellette P, \& Pilon C (1999) Health Care Spending as Determinants of Health Outcomes. Health Economics, 8(7):627-639. 1050(199911)8:7<627::AID-HEC474>3.0.CO;2-8

[11] Filmer D, \& Pritchett L (1997) Child Mortality and Public Spending on Health: How Much Does Money Matter? Working Paper No. 1864, World Bank, Washington D. C.

[12] Filmer D, \& Pritchett L (1999) The Impact of Public Spending on Health: Does Money Matter? Social Science and Medicine, 49(10): 1309-1323 http://dx.doi.org/10.1016/S0277-9536(99)00150-1.

[13] Gottret P, \& Schieber G (2006) Health Financing Revisited: A Practitioner's Guide, World Bank, Washington D.C. http://dx.doi.org/10.1596/978-0-8213-6585-4.

[14] Grossman M (1972) On the concept of health capital and the demand for health, Journal of Political Economy, 80:223-255 http://dx.doi.org/10.1086/259880.

[15] Grossman M (2000) The Human Capital Model. In Handbook of Health Economics, 2000, Vol. 1, (eds) Culyer, A. J and Newhouse, J. P., Elsevier Science BV.

[16] Gupta S, Verhoeven M, \& Tiogson E (2001) Public Spending on Health Care and the Poor, IMF Working Paper, Fiscal Affairs Department, 2001

[17] Gupta S, Verhoeven M, \& Tiongson E (2002) The Effectiveness of Government Spending on Education and Health Care in Developing and Transition Economies, European Journal of Political Economy, 18(4): 717-737. http://dx.doi.org/10.1016/S0176-2680(02)00116-7.

[18] Heijink R, Koolman X, \& Westert GP (2013) Spending more money, saving more lives? The relationship between avoidable 
mortality and healthcare spending in 14 countries, European Journal of Health Economics, 14:527-538, http://dx.doi.org/10.1007/s10198-012-0398-3.

[19] Homaie RE, Vahedi S, Teimourizad A, Esmaeilzadeh F, Hadian M, \&Torabi PA (2013) Comparison of the effects of public and private health expenditures on the health status: A panel data analysis in Eastern Mediterranean countries, International Journal of Health Policy and Management,1:163-167. http://dx.doi.org/10.15171/ijhpm.2013.29.

[20] Issa H, \& Ouattara B (2005) the Effect of Private and Public Health on Infant Mortality Rates: Does the Level of Development Matters? May $2005 . \quad$ (Available:http://citeseerx.ist.psu.edu/viewdoc/download?doi=10.1.1.63.91 $33 \&$ rep=rep1\&type=pdf)

[21] Kethineni V (1991) Political Economy of State Intervention in Health Care, Economic and Political Weekly, 26(42):2427-2433

[22] Musgrove P (1996) Public and Private Roles in Health: Theory and Financing Patterns, HNP Discussion Paper No. 339, World Bank, Washington D.C.

[23] Mushkin SJ (1962) Health as an Investment, Journal of Political Economy, 70(5): 129-157 http://dx.doi.org/10.1086/258730.

[24] Nixon J, \& Ulmann P (2006) the Relationship between Health Care Expenditure and Health Outcomes: Evidence and Caveats for a Causal Link the European Journal of Health Economics, 7(1):7-18. http://dx.doi.org/10.1007/s10198-005-0336-8.

[25] Novignon J, Nonvignon J, Mussa R, \& Chiwaula L (2012a). Health and vulnerability to poverty in Ghana: evidence from the Ghana Living Standards Survey Round 5, Health Economics Review, 2012:2. http://www.healtheconomicsreview.com/content/2/1/11. http://dx.doi.org/10.1186/2191-1991-2-11.

[26] Novignon J, Olakojo SA, \& Nonvignon J (2012b) the effects of public and private healthcare expenditure on health status in Sub-Saharan Africa: new evidence from panel data analysis, Health Economics Review, 2:22.http://www.healtheconomicsreview.com/content/2/1/22 http://dx.doi.org/10.1186/2191-1991-2-22.

[27] Or Z (2001) Exploring the Effects of Health Care on Mortality across OECD Countries, OECD Labour Market and Social Policy Occasional Papers, No. 46, OECD Directorate for Employment, Labour and Social Affairs.

[28] Peters DH, Kandola K, Elmendorf AE, \& Chellaraj G (1999) Health Expenditures, Services, and Outcomes in Africa: Basic Data and Cross-National Comparisons, 1990-1996, World Bank, Washington D. C. http://dx.doi.org/10.1596/0-8213-4438-2.

[29] Santerre RE, Grubaugh SG, \&Stoller AJ (1991) Government intervention in Health Care Markets and Health Care Outcomes: Some international evidence, Cato Journal, 11(1):1-12.

[30] Sen AK (1985) The Living Standard, The Tanner Lectures on Human Values, Delivered at Clare Hall, Cambridge University, March 11-12, 1985.

[31] Sen AK (1988) The Concept of Development, In Handbook of Development Economics, 1988, Vol. 1, (eds) Chenery, H. and Srinivasan, T. N., Elsevier Science Publishers, B. V.

[32] UNAIDS, Abuja +12, Shaping the future of health in Africa, JC2524/1/E, 2013.

[33] UNDP (1990) Human Development Report. Oxford University Press, New York.

[34] UNDP (2003), Millennium Development Goals: A Compact among Nations to End Human Poverty. United Nations Development Programme, New York.

[35] Wagstaff A (1986) the demand for health: theory and applications, Journal of Epidemiology and Community Health, 40:1-11. http://dx.doi.org/10.1136/jech.40.1.1.

[36] World Bank (1993) Investing in Health, World Development Report, Oxford University Press, Washington DC.

[37] World Bank (2004) World Development Report, World Bank, Washington D.C.

[38] World Bank (2014), World Development Indicators (WDI), World Bank, Washington, D.C. 